\title{
Developing a New Measure of Transportation Insecurity: An Exploratory Factor Analysis
}

Alix Gould-Werth, Jamie Griffin ${ }^{\dagger}$, Alexandra K. Murphy ${ }^{\ddagger}$

Tags: poverty, transportation insecurity, factor analysis

\section{Survey Practice}

Vol. 11, Issue 2, 2018

Scholarship recognizes that problems with transportation have important consequences for individual well-being and life chances. Yet no single measure exists that captures the multiple manifestations of transportation insecurity, a condition in which one is unable to regularly move from place to place in a safe and timely manner because one lacks the resources necessary for transportation. Using an original survey of 511 respondents from GfK's KnowledgePanel ${ }^{\circledR}$, we use exploratory factor analysis to estimate an initial factor structure, a step toward developing a new measure of transportation insecurity: the Transportation Security Index. Our results suggest that a two-factor solution best fits the data, and item content suggests that the factors represent the material and relational manifestations of transportation insecurity, respectively.

All authors contributed equally to this work and are listed in alphabetical order.

\section{INTRODUCTION}

People need reliable transportation to get to the places they need to go, from jobs and schools to health care and social service organizations. Yet not all people can access the transportation they need.

Using insights from our prior qualitative research on the lived experiences of low-income people (see "Methods" section), we have developed a working understanding of a condition we call transportation insecurity: A transportation insecure person cannot regularly move from place to place in a safe and timely manner because she lacks the resources she needs for transportation. Our qualitative research suggests that the symptoms of transportation insecurity fall into five domains:

- Lateness due to transportation problems

- Skipping trips due to transportation problems

- Spending a long time planning, waiting, or traveling because of one's

\footnotetext{
* Institution: Mathematica Policy Research \& University of Michigan Population Studies Center

† Institution: University of Michigan

‡ Institution: University of Michigan Department of Sociology \& the Population Studies Center
} 
transportation situation

- Social isolation due to transportation problems

- Worrying about transportation

Scholars across different disciplines currently use a diverse set of measures as proxies for transportation insecurity. For example, some of the most prominent surveys that poverty and inequality researchers draw upon ${ }^{1 *}$ ask a single question about transportation access: "Do you or anyone else in your family living here own or lease a car or other vehicle for personal use? (Yes/No)." Researchers use this data to operationalize transportation insecurity as a lack of car ownership (Fitzpatrick and Ploeg 2010; Smart and Klein 2015). Yet transportation insecurity does not correlate perfectly with car ownership. Low-income people are not always able to pay for the gas, repairs, and insurance required to drive their own cars (Blumenberg and Agrawal 2014). Furthermore, car-owning low-income families might not have enough vehicles to satisfy the transportation needs of each household member (Pendall et al. 2 014).

Urban planners combine census, land use, transit, and survey data to create place-based metrics of communities along scales of "transit richness" or "neighborhood accessibility" (Grengs 2012). Our qualitative research revealed, however, that within neighborhoods, one resident might be able to take the local bus, whereas another might not because of fare costs, health conditions, or safety concerns. In other words, transportation insecure people sometimes live in "transit rich" neighborhoods.

Finally, health and aging researchers measure some or all of the "five As of access:" availability, accessibility, accommodation, affordability, and acceptability (Arcury et al. 2005; Sagrestano et al. 2014). Although many of their measures address one or more dimensions of transportation insecurity as we define it, no consistent measure is used across these studies (for an overview, see (Syed, Gerber, and Sharp 2013)). ${ }^{2}$ Instead, measures are often tailored to the subpopulation of interest, making it difficult to compare findings across populations and health-related outcomes as well as between health-related domains and other domains, like employment.

To develop a single measure of transportation insecurity at the individual level that can be used across disciplines and within different domains of interest, we used the Food Security Index (FSI) as our model. The FSI is a

\footnotetext{
1 These include the Panel Study of Income Dynamics and the Fragile Families and Child Wellbeing Study.

2 For example, Sagrestano et al. (2014) examine the relationship between "transportation vulnerability" among HIV-positive individuals and service utilization. Though they do not develop a definition of their concept of transportation vulnerability, they use all of the "five As of access" to measure the phenomenon at the individual level. In contrast, in their study of the impact of transportation vulnerability on HIV linkage to care and viral suppression, (Goswami et al. 2016) define transportation vulnerability as "restriction of a resident's ability to utilize available transportation" (p. 2) and operationalize it as public transit access and car ownership at the ZIP code tabulation area level.
} 
multidimensional measure capturing "uncertain, insufficient, or unacceptable availability, access or utilization of food" due to a lack of financial resources (National Research Council 2006), pg.4. Rather than attempting to measure the content of what people eat, the FSI was explicitly designed to directly "measure food insecurity based on the way people actually experience it" (Fron gillo 1999): 507S. Thus, FSI items capture symptoms of experiences with food insecurity, asking questions, such as: "In the last 12 months, did you ever eat less than you felt you should because there wasn't enough money for food?"3

Similarly, the items we considered including in the Transportation Security Index (TSI) measure the symptoms of experiences with transportation insecurity (e.g. "In the past 30 days, how often have you had to reschedule an appointment because of a problem with transportation?"). By measuring symptoms rather than neighborhood context or mode of travel, researchers can, with a single measure, differentiate car owners who can and cannot afford gas; people who can walk to the places they need to go and people who are stranded without a car; and transportation secure residents and their transportation insecure neighbors. Although designed to advance our understanding of how transportation insecurity affects poverty and inequality, measuring transportation insecurity directly will also help researchers better understand its causes and consequences in other domains, such as employment, health, and education.

\section{METHODS}

Questionnaire design. Questionnaire content was informed by extensive qualitative research. For 3.5 years, Murphy (forthcoming) conducted interviews with, and made ethnographic observations of everyday life among, poor African American residents living in a Pittsburgh suburb. In Metropolitan Detroit, (Gould-Werth 2015) interviewed 45 workers following job loss. In both sites, respondents faced significant problems with transportation. Both researchers observed the material manifestations of transportation insecurity (e.g. skipping trips). In addition, Murphy's ethnographic methods allowed her to observe its relational manifestations (e.g. strained relationships with ride-givers). Based on these observations, the two researchers developed a suite of potential TSI items, which they circulated to qualitative researchers, service providers, and people with low incomes for input on item content and wording.

Using the revised items, we conducted an iterative series of 52 cognitive interviews with a socioeconomically and demographically diverse group of

\footnotetext{
3 The FSI was originally created to address the problem of researchers measuring food insecurity using different "indirect indicators, often with unknown validity" (Frongillo et al. 1997): 506S, such as the percentage of people in poverty or on Food Stamps (Frongillo et al. 1997). For more on the history of the development of the FSI, see (Carlson, M., and Bickel 1999); (Radimer, Olson, and Campbell 1990); (Campbell 1991). Using a single, valid index, researchers have shown food insecurity to be related to a variety of outcomes from depression and malnutrition to education (Nord and Prell 2007). A single measure has also allowed researchers to generate estimates of the prevalence and distribution of food insecurity across the United States (Coleman-Jensen et al. 2017).
} 
people. We identified respondents through nonprofit organizations and by door knocking and snowball sampling in Chicago and urban, suburban, and rural Michigan. ${ }^{4}$ We coded responses for question comprehension, recall, and judgement. Burdensome items were refined, items generating false positives were dropped, and new items were developed to capture transportation insecurity among the chronically insecure. ${ }^{5}$ Our analysis resulted in a set of 23 potential TSI items. We then designed a questionnaire that included these items, as well as measures of household size, household income, material hardship, employment status, and disability status (See Appendix A). ${ }^{6}$

Data collection methods. We contracted with The GfK Group for the survey's administration. GfK maintains the KnowledgePanel®, the first online research panel that is representative of the U.S. population. ${ }^{7}$ Panel members are recruited using probability-based sampling ${ }^{8}$ and an address-based sample frame. ${ }^{9}$ Notably, the KnowledgePanel ${ }^{\circledR}$ sample frame has improved coverage (over random-digit dial samples) of minority racial and ethnic groups and low-income households (DiSogra, M., and Hendarwan 2009)-groups that are of particular interest to the current study.

Although the KnowledgePanel ${ }^{\circledR}$ is designed to be nationally representative, this stage of the measure development process depended on having a sample that exhibited variable levels of transportation insecurity. Thus, we selected a stratified sample of three approximately equal groups defined by household income: less than $\$ 15,000 ; \$ 15,000-\$ 29,999$; and $\$ 30,000$ or more.

Between August 9 and August 17, 2016, 511 members of the panel completed the survey (completion rate ${ }^{10}=50 \%$ ). GfK also shared standard demographic information for respondents (see Table 1).

\footnotetext{
4 Respondents were paid $\$ 40$ for their time. Interviews lasted roughly 1.5 hours. In addition to TSI items, the interview guide included questions about respondents' financial and transportation situations as well as demographic characteristics.

5 These items asked about advance planning, making backup plans, and only going places if it is important to go.

6 These questions were adopted or adapted from existing surveys, including the General Social Survey, the Panel Study of Income Dynamics Main Interview, and the National Household Travel Survey

7 Samples from the panel have been demonstrated to closely resemble U.S. Census demographic benchmarks (Yeager et al. 2011).

8 GfK uses a patented methodology to ensure that all general population samples are fully self-weighting (i.e., each sample member is assigned a design weight of unity). Study-specific design weights are adjusted to account for any departure from a general population sample (e.g., stratified design, oversampling) and any differential nonresponse.

9 Members are provided with Internet access and a Web-enabled device, if necessary (GfK n.d.).

10 The completion rate, a response metric commonly used in panel surveys, is the proportion of eligible sample members (i.e., those who consented to participate in the panel and who completed any relevant profile surveys) (denominator) who have completed the survey in question (numerator) )(Callegaro and DiSogra 2009). Note that the completion rate does not take into account the initial response rate to the original panel invitation.
} 
Table 1. Survey respondent characteristics $(N=511)$.

\begin{tabular}{|c|c|}
\hline & $\%$ \\
\hline \multicolumn{2}{|l|}{ Age } \\
\hline $18-29$ & 9.2 \\
\hline $30-44$ & 20.9 \\
\hline $45-59$ & 28.2 \\
\hline $60+$ & 41.7 \\
\hline \multicolumn{2}{|l|}{ Gender } \\
\hline Female & 49.7 \\
\hline \multicolumn{2}{|l|}{ Race/Ethnicity } \\
\hline White, non-Hispanic & 64.6 \\
\hline Black, non-Hispanic & 13.3 \\
\hline Hispanic & 14.1 \\
\hline Other & 8.0 \\
\hline \multicolumn{2}{|l|}{ Education } \\
\hline Less than high school & 15.7 \\
\hline High school & 38.6 \\
\hline Some college & 26.2 \\
\hline Bachelor's degree or higher & 19.6 \\
\hline \multicolumn{2}{|l|}{ Region } \\
\hline Northeast & 15.7 \\
\hline Midwest & 22.9 \\
\hline South & 37.4 \\
\hline West & 24.1 \\
\hline \multicolumn{2}{|l|}{ Household income } \\
\hline$<\$ 15,000$ & 33.5 \\
\hline$\$ 15,000-\$ 29,999$ & 29.3 \\
\hline$\$ 30,000$ or more & 37.2 \\
\hline$\$ 30,000-\$ 49,999$ & 12.7 \\
\hline$\$ 50,000-\$ 74,999$ & 8.2 \\
\hline$\$ 74,999$ or more & 16.3 \\
\hline \multicolumn{2}{|c|}{ Presence of personal vehicle in household } \\
\hline Yes & 61.6 \\
\hline No & 36.4 \\
\hline Refused & 2.0 \\
\hline
\end{tabular}

Analytic approach. Following DeVills' (DeVellis 2017) scale development guidelines, we first examined the correlation matrix and individual item response distributions. To determine the scale's dimensionality, we used exploratory factor analysis. ${ }^{11}$ We evaluated the scale's reliability by estimating Cronbach's alpha and each individual item's alpha-if-item-deleted coefficient. Finally, as a preliminary means of evaluating the final scale's concurrent validity, we examined how well the estimated index scores differentiated between respondents classified as secure or insecure based on other observed

11 Exploratory factor analysis is a data reduction technique that has the goal of reproducing the observed correlation matrix by defining latent (i.e., unobserved) factors that are linear combinations of the individual observed items. 
proxies for transportation security. Because three respondents did not respond to any of the 23 potential TSI items, our analytic sample consisted of 508 respondents. Notably, at this stage of the measurement development process, we were not interested in extrapolating our findings to the general population; thus, unweighted data were analyzed.

\section{RESULTS}

Descriptive statistics. First, we examined the correlation matrix to identify items that were highly correlated. We defined a high level of correlation as $r$ $\geq 0.7$. We found that important to go was not highly correlated with any item in the item pool and that advance planning and backup plan were highly correlated with only one other item. Similarly, felt unsafe and police stop each had four high correlations. Conversely, the majority of the remaining items were highly correlated with at least half of the item pool.

Next, we considered each item's response distribution to identify items that exhibited little variability. As illustrated in Figure 1, respondents were most likely to agree that they only went places if it was important to go (43.9\%), that they usually had a backup plan (32.7\%), and that they planned their trips in advance (advance planning: $32.0 \%$ ). Conversely, respondents were least likely to report that they had to reschedule appointments (3.2\%) or skipped going places $(3.8 \%)$ or felt that they were not able to leave house (4.2\%) because of problems with transportation. Similarly, concerns about feeling unsafe (felt unsafe: $4.8 \%$ ) and being stopped by police (police stop: $5.0 \%$ ) because of the transportation they used were uncommon. 


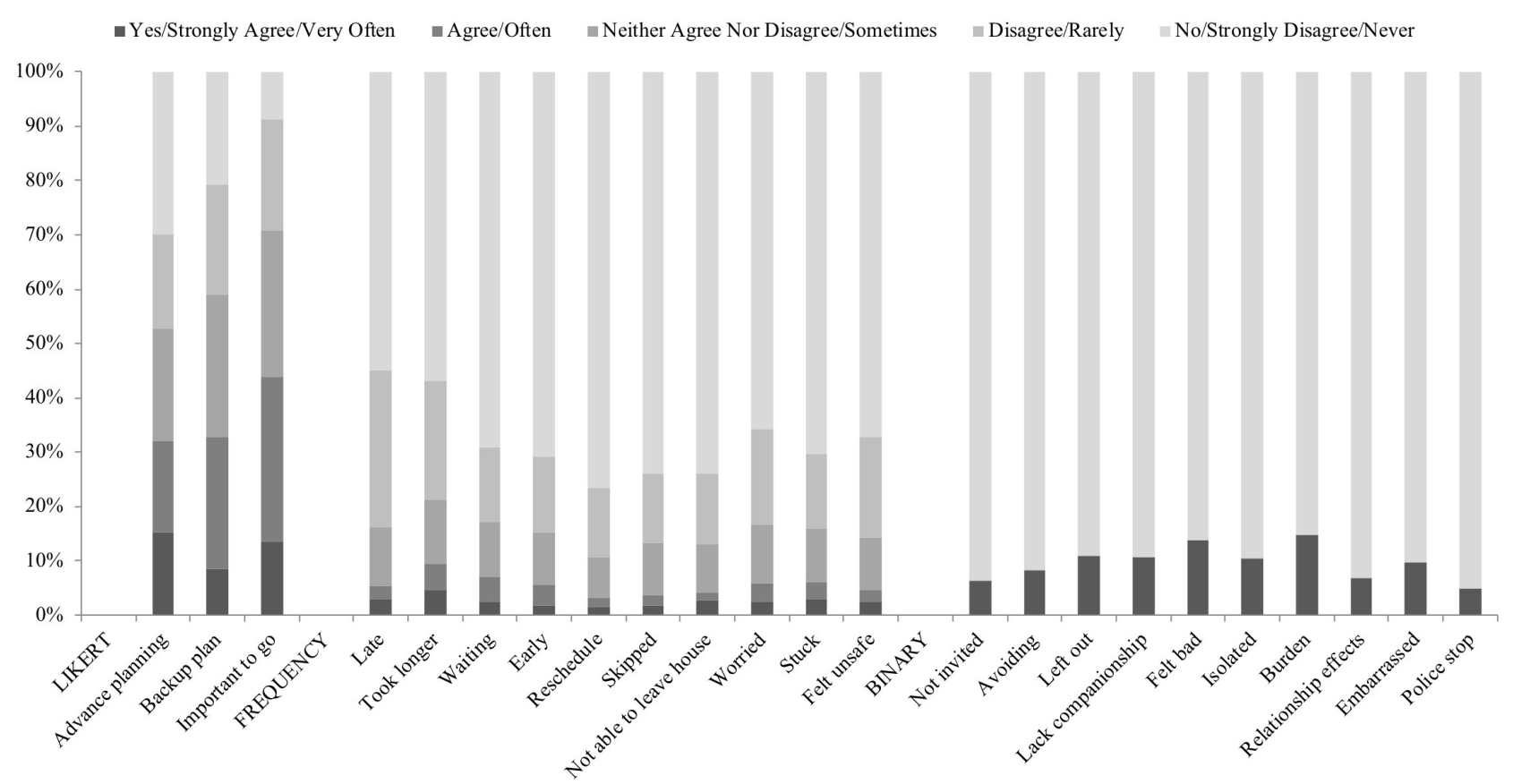

Figure 1.

Individual item response distributions. Based on these descriptive statistics, we struck seven items from the index: advance planning, backup plan, important to go, felt unsafe, and police stop. Finally, we struck lack companionship and isolated because they were redundant with left out: these three items comprise the short-form of the UCLA Loneliness Scale (Hughes et al. 2004). Thus, 16 of the original 23 items remained candidates for inclusion in the index.

Exploratory factor analysis. We considered one- and two-factor solutions to an exploratory factor analysis with an oblique (Geomin) rotation estimated using Mplus Version 7.3; (Muthén and Muthén 1998). As illustrated in Table 2, in the one-factor solution, all items loaded highly on the latent factor; however, the model fit indices (see Table 3 ) suggested that the model poorly fit the data (root mean square error of approximation $[\mathrm{RMSEA}]=.091$ ). The estimation of a second dimension resulted in improved model fit (RMSEA $=.063$ ). Importantly, in the two-factor solution, both dimensions were theoretically and empirically interpretable: the material dimension addresses how problems with transportation affect one's ability to get to places one needs to go in a timely manner, whereas the relational dimension addresses how problems with transportation affect one's relationships with others. Indeed, in our qualitative research, we observed transportation insecurity manifesting in precisely these domains. 
Table 2. Factor loadings (SEs) and unit-weighted score distributions.

\begin{tabular}{|c|c|c|c|c|}
\hline \multirow{2}{*}{ Item } & & \multirow{2}{*}{$\begin{array}{l}\text { One dimension } \\
\text { General }\end{array}$} & \multicolumn{2}{|c|}{ Two dimensions $^{b}$} \\
\hline & & & Material $^{c}$ & Relational $^{d}$ \\
\hline 5 & Late & $0.763(.025)$ & $0.891(.078)$ & $-0.117(.097)$ \\
\hline 6 & Took longer & $0.830(.020)$ & $0.961(.057)$ & $-0.125(.068$ \\
\hline 7 & Waiting & $0.874(.017)$ & $0.891(.026)$ & $0.007(.026)$ \\
\hline 8 & Early & $0.848(.020)$ & $0.880(.049)$ & $-0.013(.056$ \\
\hline 9 & Reschedule & $0.893(.017)$ & $0.848(.075)$ & $0.078(.094)$ \\
\hline 10 & Skipped & $0.906(.013)$ & $0.782(.068)$ & $0.168(.079)$ \\
\hline 11 & Not able to leave house & $0.928(.011)$ & $0.815(.068)$ & $0.154(.081)$ \\
\hline 12 & Worried & $0.926(.011)$ & $0.717(.066)$ & $0.264(.077)$ \\
\hline 13 & Stuck & $0.928(.010)$ & $0.635(.066)$ & $0.362(.074)$ \\
\hline 14 & Not invited & $0.933(.023)$ & $0.108(.089)$ & $0.875(.075)$ \\
\hline 15 & Avoiding & $0.918(.021)$ & $-0.006(.035)$ & $0.958(.034)$ \\
\hline 16 & Left out & $0.952(.014)$ & $0.069(.074)$ & $0.921(.060)$ \\
\hline 18 & Felt bad & $0.944(.014)$ & $-0.011(.068)$ & $0.981(.054)$ \\
\hline 20 & Burden & $0.839(.027)$ & $0.019(.076)$ & $0.879(.068)$ \\
\hline 21 & Relationship effects & $0.924(.023)$ & $0.112(.092)$ & $0.865(.077)$ \\
\hline 22 & Embarrassed & $0.904(.023)$ & $-0.096(.082)$ & $1.022(.064)$ \\
\hline \multicolumn{5}{|c|}{ Unit-weighted factor score distributions } \\
\hline \multicolumn{2}{|c|}{ Mean (SD) } & not calculated & $4.96(7.21)$ & $0.70(1.70)$ \\
\hline \multicolumn{2}{|c|}{ Median } & not calculated & 2 & 0 \\
\hline \multicolumn{2}{|c|}{ Minimum } & not calculated & 0 & 0 \\
\hline \multicolumn{2}{|c|}{ Maximum } & not calculated & 36 & 7 \\
\hline
\end{tabular}

Note: $\mathrm{SE}=$ standard error; $\mathrm{SD}=$ standard deviation.

atem number corresponds to item number in the questionnaire included in Appendix A. See questionnaire for complete item wording.

${ }^{\mathrm{b}}$ Factor loadings in bold indicate to which factor each item was ultimately assigned.

${ }^{\mathrm{c}}$ Material items were scored $0=$ strongly disagree to $4=$ strongly agree; thus, possible unit-weighted factor scores ranged from 0 to 36 .

${ }^{\mathrm{d}}$ Relational items were scored $0=$ no to $1=y e s$; thus, possible unit-weighted factor scores ranged from 0 to 7 .

Table 3. Model fit indices.

\begin{tabular}{llll}
\hline Model & Global fit indices & & Factor \\
& RMSEA & CFI & correlation \\
1 dimension & 0.091 & 0.979 & \\
2 dimensions & 0.063 & 0.991 & 0.753
\end{tabular}

Note. RMSEA = root mean square error of approximation; CFI = comparative fit index. RMSEA $\leq .05$ close approximate fit, $>.05-.08$ reasonable error of approximation, >.08-<.10 mediocre fit, $\geq .10$ poor fit (Browne and Cudeck 1993; MacCallum et al. 1996). CFI $\geq .90$ reasonably good fit (Hu and Bentler 1999).

Reliability. To evaluate the internal consistency of each dimension separately, we estimated Cronbach's alpha. Both dimensions exhibited acceptable reliability (Nunnally 1978): material: $\alpha=0.95$ and relational: $\alpha=0.91$. Similarly, removal of any of the items from either dimension did not result in improved scale reliability. As illustrated in Table 2, items 5 through 13 and items 14 through 22 represent the material and relational manifestations of transportation insecurity, respectively. 
Validity. Finally, we evaluated the two-dimensional TSI's concurrent validity. ${ }^{12}$ Because there is no current gold standard measurement of transportation security, we used survey items that were not part of the index to manually classify respondents as transportation secure or insecure. Certainly, both the two-dimensional TSI and our manual classification of respondents are imperfect measures of the phenomenon; however, the concordance of the two measures provides preliminary evidence that the TSI is capturing the intended construct.

First, we calculated each respondent's material and relational scores by summing their responses to the items comprising each of the index's two dimensions. ${ }^{13}$ Then, we identified a group of respondents expected to exhibit lesser transportation insecurity than others. To do this we drew on our previous qualitative work $^{14}$ to define this likely secure group as: household income $\geq$ $\$ 75,000$, having a car for personal use within the household, having a valid license, and not reporting a disability. A total of 66 respondents were categorized as likely secure.

Finally, we identified a group of respondents expected to exhibit greater levels of transportation insecurity than others. Again, drawing on our previous qualitative work, we defined this likely insecure group as reporting problems paying for transportation and reporting at least one of the following: trouble paying for rent, mortgage, or utility bills or disconnection of utilities or telephone service. In total, 30 respondents were categorized as likely insecure. No respondents fell into both the likely secure and likely insecure groups. ${ }^{15}$

As hypothesized (see Table 4), secure respondents were less likely to experience the material aspects of transportation insecurity than were their counterparts (mean material scores were 2.21 vs. 5.37, respectively; Welch's $t(120.19)=$ $4.62, p<.001)$. Similarly, the 30 insecure respondents were more likely to experience the material aspects of transportation insecurity than were their counterparts (mean material scores were 13.33 vs. 4.44, respectively; Welch's $t(30.82)=-4.88, p<.001)$.

Among all 508 respondents, relational scores ranged from 0 to 7 ; however, $78.4 \%$ of respondents had a score of 0 . Because of the skewed distribution, we dichotomized the relational scores to differentiate the 398 respondents with a score of 0 from the remaining 110 respondents with a score of at least 1 . As hypothesized, the 66 secure respondents were less likely to experience the

12 Concurrent validity is a measure of each dimension's ability to differentiate between respondents who are transportation secure and respondents who are transportation insecure.

13 Note that we did not calculate a "total score;" rather, we examined sum scores to each dimension separately.

14 Previous qualitative work refers to (Gould-Werth 2015), Murphy (forthcoming), as well as the cognitive interviews we conducted for this research.

15 Note that the "likely secure" and "likely insecure" constructs are extremes that are not intended to capture the broad groups of secure and insecure individuals. Our aim was to identify the extreme ends of the distribution in order to see how the measure operated among those respondents whose transportation security status we could most confidently manually classify. 
relational aspects of transportation insecurity than were their counterparts ( $4.6 \%$ vs. $24.2 \%$, respectively; $\chi 2(1)=13.09, p<.001)$. Similarly, the 30 insecure respondents were more likely to experience the relational aspects of transportation insecurity than were their counterparts $(70.0 \%$ vs. $18.6 \%$, respectively; $\chi 2(1)=43.93, p<.001)$. 
Table 4. Comparison of factor scores by likely secure/insecure status.

\begin{tabular}{|c|c|c|c|c|}
\hline & \multicolumn{2}{|c|}{ Material } & \multicolumn{2}{|c|}{ Relational } \\
\hline & Defined as "likely secure" & Not defined as "likely secure" & Defined as "likely secure" & Not defined as "likely secure" \\
\hline mean & 2.21 & 5.37 & 0.046 & 0.242 \\
\hline$n$ & 66 & 442 & 66 & 442 \\
\hline \multirow[t]{2}{*}{ Statistical significance } & & Welch's $t=4.62^{* * *}$ & & $x^{2}=13.09^{* * *}$ \\
\hline & Defined as "likely insecure" & Not defined as "likely insecure" & Defined as "likely insecure" & Not defined as "likely insecure" \\
\hline mean & 13.31 & 4.44 & 0.7 & 0.186 \\
\hline$n$ & 30 & 478 & 30 & 478 \\
\hline Statistical significance & & Welch's $t=-4.88^{* * *}$ & & $x^{2}=43.93^{* * *}$ \\
\hline
\end{tabular}

Note: ${ }^{* * *}=\mathrm{p}<.001$, Among all 508 respondents, material scores ranged from 0 to 36 , with a mean of 4.96, standard deviation of 7.21 , and median of 2 ; relational scores ranged from 0 to 1 , with a mean of 0.22 . 
Together, these results suggest that both dimensions of the TSI meaningfully distinguish among respondents with different levels of transportation security.

\section{DISCUSSION}

Using data from an original survey administered to a subsample of GfK's KnowledgePanel ${ }^{\circledR}$, we identified 16 items that measure the material (nine items) and relational (seven items) manifestations of transportation insecurity. Furthermore, we demonstrated that these two dimensions successfully differentiate between groups that they are expected to differentiate between (likely secure and likely insecure respondents).

Because of this study's preliminary nature, there are several limitations. By definition, exploratory factor analysis does not permit the statistical evaluation of specific hypotheses about the index's psychometric properties. For example, we cannot evaluate whether the structure of the index is the same for various demographic groups (such as age, race, and location). Similarly, we cannot, with confidence, evaluate whether associations between the index and various outcomes vary by demographic groups. Future research will employ confirmatory psychometric methods (e.g., confirmatory factor analysis, structural equation modeling) to address these important questions. Furthermore, our approach will incorporate complex sample design features (e.g., stratification, survey weights), permitting us to extrapolate our findings to the general population.

Despite these limitations, this research holds important implications for scholarship and policy. A single, valid index that directly measures transportation insecurity as it is experienced by people will enable scholars to examine the causes and consequences of transportation insecurity among different demographic groups and within different domains (e.g., health, employment, housing). In doing so, the TSI will deepen our understanding of the role transportation plays in causing, reproducing, and ameliorating poverty. Designed to capture people's ability to get to places regardless of their mode of transportation, the TSI is uniquely positioned to enable researchers to examine how new transportation technologies (e.g., autonomous vehicles) impact inequality in transportation security. The TSI will also enable planners and policymakers to evaluate the impact of policy changes (e.g., public transit route eliminations or additions, public transit fare subsidies) on transportation insecurity and related outcomes.

We hope that others will use the current 16-item TSI in their research. We anticipate that our ongoing evaluation of the index's psychometric properties and performance might improve the measure. To that end, in spring 2018 we fielded a nationally representative survey $(N=2,000)$. With these new data we will replicate and extend the current analyses to: (1) ensure that our results are not specific to the sample; (2) determine whether a more parsimonious measure of transportation insecurity has the same predictive power as the 16 
items identified here; and (3) generate national and subgroup (race, geography, age) prevalence estimates of transportation insecurity.

\section{ACKNOWLEDGEMENTS}

The authors thank Mike Bader, David Pedulla, Jeffrey Morenoff, Elisabeth Gerber, Conan Smith, the members of the University of Michigan Survey Design Group, and the anonymous reviewers of Survey Practice for their helpful comments. We are grateful to Tia Clinton, Bri Gauger, Karina Lopez, and Shoshana Shapiro for their assistance conducting cognitive interviews as well as Lisa Holland for her consultation on this process. This work was supported by grants from the Gerald R. Ford School of Public Policy's Center for Public Policies in Diverse Societies, Stanford University's Center on Poverty and Inequality, and University of Michigan's Poverty Solutions as well as a NICHD center grant to the Population Studies Center at the University of Michigan (P2CHD041028). Additionally, this research was partially supported by the Stanford Center on Poverty and Inequality through funding provided by grant number H79AE000101 from the U.S. Department of Health and Human Services (Office of the Assistant Secretary for Planning and Evaluation). The contents of this report are solely the responsibility of the authors and do not necessarily reflect the views or official policies of the U.S. Department of Health and Human Services; nor does mention of trade names, commercial practices, or organizations imply endorsement by the U.S. Government or by any of these entities.

\section{APPENDIX A:}

SUMMER 2016 TRANSPORTATION SURVEY

\section{A. YOUR TRANSPORTATION}

\section{Base: All Qualified respondents}

\section{Q1 [Grid, SP across]}

How often do you use each of the following to get from place to place?

Statements in row:

1. Walk

2. Bike

3. Your own personal vehicle (e.g., car, truck, SUV)

4. The personal vehicle of a friend, family member, or neighbor

5. Taxi service or rideshare (e.g., Uber, Lyft)

6. Rental car or car sharing service (e.g., zipcar, Car2go)

7. Bus

8. Train or subway

9. Paratransit (that is, specialized, door-to-door transport service for people with disabilities)

Statements in column: 


\section{Daily}

2. A few times a week

3. A few times a month

4. A few times a year

5. Never

\section{Base: All Qualified respondents}

How much do you agree or disagree with the following statements?

Statements in row:

Q3 (advance planning) When I need to get somewhere, I usually spend time planning out how I will get there. For example, I spend time figuring out the schedule of buses or trains, who can give me a ride, or how to come up with the money I need for gas, fare, or to otherwise pay for the ride.

Q4 (backup plan) When I need to go someplace, I think about a backup plan in case I end up having a problem with the transportation I am using.

Q5 (important to go) I usually go places only if it is really important to go.

Statements in column:

1. Strongly agree

2. Agree

3. Neither agree nor disagree

4. Disagree

5. Strongly disagree

\section{Base: All Qualified respondents}

\section{Q6 (late) [S] - material}

During a typical week, people might walk, bike, take a bus, train or taxi, drive a car, or get a ride to get to the places they need to go. In the past 30 days, how often have you been late getting somewhere because of a problem with transportation?

1. Very often

2. Often

3. Sometimes

4. Rarely

5. Never

\section{Base: All Qualified respondents}

\section{Q7 (took longer) [S] - material}

In the past 30 days, how often did it take you longer to get somewhere than it would have taken you if you had different transportation?

1. Very often 
2. Often

3. Sometimes

4. Rarely

5. Never

\section{Base: All Qualified respondents}

Q8 (waiting) [S] - material

There are times when we need to wait for transportation to pick us up. In the past 30 days, how often have you spent a long time waiting because you did not have the transportation that would allow you to come and go when you wanted?

1. Very often

2. Often

3. Sometimes

4. Rarely

5. Never

\section{Base: All Qualified respondents}

\section{Q9 (early) [S] - material}

In the past 30 days, how often did you have to arrive someplace early and wait because of the schedule of the bus, train, or person giving you a ride?

1. Very often

2. Often

3. Sometimes

4. Rarely

5. Never

\section{Base: All Qualified respondents}

\section{Q10 (reschedule) [S] - material}

In the past 30 days, how often have you had to reschedule an appointment because of a problem with transportation?

1. Very often

2. Often

3. Sometimes

4. Rarely

5. Never

\section{Base: All Qualified respondents}

Q11 (skipped) [S] - material

In the past 30 days, how often have you skipped going someplace because of a problem with transportation?

1. Very often 
2. Often

3. Sometimes

4. Rarely

5. Never

\section{Base: All Qualified respondents}

Q12 (not able to leave house) [S] - material

In the past 30 days, how often have you not been able to leave the house when you wanted to because of a problem with transportation?

1. Very often

2. Often

3. Sometimes

4. Rarely

5. Never

\section{Base: All Qualified respondents}

\section{Q13 (worried) [S] - material}

In the past 30 days, how often have you worried about whether or not you would be able to get someplace because of a problem with transportation?

1. Very often

2. Often

3. Sometimes

4. Rarely

5. Never

\section{Base: All Qualified respondents}

Q14 (stuck) [S] - material

In the past 30 days, how often did you feel stuck at home because of a problem with transportation?

1. Very often

2. Often

3. Sometimes

4. Rarely

5. Never

\section{Base: All Qualified respondents}

Q15 (not invited) [S] - relational

In the past 30 days, do you think that someone did not invite you to something because of problems with transportation?

1. Yes

2. No 


\section{Base: All Qualified respondents}

Q16 (avoiding) [S] - relational

In the past 30 days, have you felt like friends, family, or neighbors were avoiding you because you needed help with transportation?

1. Yes

2. No

\section{Base: All Qualified respondents}

Q17 (left out) [S] - relational

In the past 30 days, have you felt left out because you did not have the transportation you needed?

1. Yes

2. No

\section{Base: All Qualified respondents}

Q18 (lack companionship) [S]

In the past 30 days, have you felt that you lack companionship because you did not have the transportation you needed?

1. Yes

2. No

\section{Base: All Qualified respondents}

Q19 (felt bad) [S] - relational

In the past 30 days, have you ever felt bad because you did not have the transportation you needed?

1. Yes

2. No

\section{Base: All Qualified respondents}

Q20 (isolated) [S]

In the past 30 days, have you felt isolated from others because you did not have the transportation you needed?

1. Yes

2. No

\section{Base: All Qualified respondents}

\section{Q21 (burden) [S] - relational}

In the past 30 days, have you ever worried about inconveniencing your family, friends, or neighbors because you needed help with transportation?

1. Yes 
2. No

Base: All Qualified respondents

Q22 (relationship effects) [S] - relational

In the past 30 days, have problems with transportation affected your relationships with others?

1. Yes

2. No

\section{Base: All Qualified respondents}

Q23 (embarrassed) [S] - relational

In the past 30 days, have you ever felt embarrassed because you did not have the transportation you needed?

1. Yes

2. No

\section{Base: All Qualified respondents}

Q24 (felt unsafe) [S]

In the past 30 days, how often have you felt unsafe while going somewhere because of the transportation you were using? Please include times when you were walking or riding a bike, taking public transit, waiting for a ride, riding in a car that needed repairs, or getting rides with others.

1. Very often

2. Often

3. Sometimes

4. Rarely

5. Never

\section{Base: All Qualified respondents}

\section{Q25 [S]}

In the past 30 days, did you ever pay more to buy something at a store you could get to because you did not have the transportation you needed to go to a store with lower prices?

1. Yes

2. No

\section{Base: All Qualified respondents}

Q26 (police stop) [S]

Sometimes the police stop and question us while we are driving, waiting for a ride, walking, or riding a bike. In the past 12 months, were you ever stopped by the police while going someplace because of the type of transportation you were using? 
1. Yes

2. No

\section{Base: All Qualified respondents}

Q27 [S]

Can you usually afford the transportation you need?

1. Yes

2. No

\section{Base: All Qualified respondents}

\section{Q28 [Grid, SP across]}

In past 30 days, have you had trouble paying for any of the following?

Statements in row:

1. Gas

2. Car insurance

3. Car registration

4. Car repairs

5. Outstanding traffic tickets (e.g., speeding, parking, driving without a license)

6. Paying a friend, family member, or neighbor for a ride

7. Taxi service or rideshare (e.g., Uber, Lyft)

8. Rental car or car sharing service (e.g., zipcar, Car2go)

9. Bus fare

10.Train or subway fare

Statements in column:

1. Yes

2. No

\section{Base: All Qualified respondents}

\section{Q29 [S]}

Do you have a valid driver's license?

1. Yes

2. No

\section{Base: All Qualified respondents}

[PPHHSIZE]

QSIZE [Q]

Including yourself, how many people currently live in your household at least $50 \%$ of the time?

\section{[SPACE]}

Please remember to include babies or small children, include unrelated 
individuals (such as roommates), and also include those now away traveling, at school, or in a hospital.

Type in the number for the answer.

SCRIPTER: min. $=1$, ax. $=15$; do not allow decimals

Base: All Qualified respondents

Q30 [S]

Do you or does anyone else in your household own or lease a car or other vehicle for personal use?

1. Yes

2. No

Base: $Q 29=1$ or $Q 29$ is missing

Q31 [S]

What is the year, make, and model of the vehicle you use most of the time?

Year ___ [dropdown menu - 1900-2017;please display years in descending order i.e. 2017 appears first]

Make [dropdown menu; please use the MAKE MODEL CODES_V1.01.XLSX saved in the DR]

Model [dropdown menu; please use the MAKE MODEL CODES_V1.01.XLSX saved in the DR]

Base: $Q 29=1$ or $Q 29$ is missing

Q32 [S]

Can you rely on this vehicle to get you to school, work, or other places?

1. Yes

2. No

Base: Q29=1 or Q29 is missing

Q33 [S]

Is this vehicle currently covered by car insurance?

1. Yes

2. No

Base: All Qualified respondents

Q34 [S]

How long would it take you to get to the nearest bus, train, or subway stop?

1. Less than 15 minutes

2. 15 to 30 minutes

3. 31 to 45 minutes 
4. 46 minutes to 1 hour

5. More than 1 hour

Base: All Qualified respondents

Q35 [S]

How many people can you ask for a ride if you need one?

1. 0 SKIP TO QUESTION 36

2. 1

3. 2

4. 3 to 5

5.6 or 7

6. 8 or more

Base: ask if $Q 34=2$ to 6 or $Q 34=$ missing

Q36 [S]

How many of these people live in your neighborhood?

1. 0

2. 1

3. 2

4. 3 to 5

5.6 or 7

6. 8 or more

\section{Base: All Qualified respondents}

\section{Q37 [S]}

How often do people ask you for a ride somewhere?

1. Very often

2. Often

3. Sometimes

4. Rarely

5. Never

\section{Base: All Qualified respondents}

\section{Q38 [S]}

How many of the people that you know have trouble getting to the places they need to go?

1. All

2. Most

3. Some

4. A few

5. None 


\section{B. YOUR HEALTH AND WELBEING}

\section{Base: All Qualified respondents}

\section{Q39 [S]}

Do you have a temporary or permanent condition or handicap that makes it difficult to travel outside of the home?

1. Yes

2. No

Base: $\mathrm{Q} 39=1$ or $\mathrm{Q} 39=$ missing

Q40 [S]

Do you use anything to help you walk or get around, such as a cane, seeing-eye dog, or wheelchair?

1. Yes

2. No

Base: $\mathrm{Q} 39=1$ or $\mathrm{Q} 39=$ missing

Q41 [Grid, SP across]

Because of this condition, have you ever done the following?

Statements in row:

1. Reduced your day-to-day travel

2. Asked others for rides

3. Limited driving to daytime

4. Given up driving altogether

5. Used the bus or subway less frequently

6. Used special transportation services such as Dial-A-Ride

7. Used a reduced fare taxi

Statements in column:

1. Yes

2. No

\section{YOUR SOCIAL BENEFIT RECEIPT}

\section{Base: All Qualified respondents}

[PPINCIMP]

\section{QINCINTRO}

The next question is about the total income of YOUR HOUSEHOLD for the PAST 12 MONTHS. Please include your income PLUS the income of all members living in your household (including cohabiting partners and armed forces members living at home). Please count income BEFORE TAXES and from all sources (such as wages, salaries, tips, net income from a business, 
interest, dividends, child support, alimony, and Social Security, public assistance, pensions, or retirement benefits).

\section{Base: All Qualified respondents}

Q41 QINC [S]

Was your total HOUSEHOLD income in the past 12 months...

Select one answer only.

1. Below $\$ 35,000$

2. $\$ 35,000$ or more

3. Don't know

SCRIPTER: Prompt once if question is skipped. Do not show 'Don't know' initially. Show 'Don't know' only with the prompt if question is skipped initially.

\section{[PROMPT]}

We'd like you to answer this question because it's important for future surveys. We greatly appreciate your response and will keep your individual answer confidential.

\section{Base: Respondents with HH income below \$35,000 (QINC = 1)}

Q42 [S]

We would like to get a better estimate of your total HOUSEHOLD income in the past 12 months before taxes. Was it...

Select one answer only.

1. Less than $\$ 5,000$

2. $\$ 5,000$ to $\$ 7,499$

3. $\$ 7,500$ to $\$ 9,999$

4. $\$ 10,000$ to $\$ 12,499$

5. $\$ 12,500$ to $\$ 14,999$

6. $\$ 15,000$ to $\$ 19,999$

7. $\$ 20,000$ to $\$ 24,999$

8. $\$ 25,000$ to $\$ 29,999$

9. $\$ 30,000$ to $\$ 34,999$

Base: Respondents with household income of $\$ 35,000$ or more (QINC =2)

\section{Q43 [S]}

We would like to get a better estimate of your total HOUSEHOLD income in the past 12 months before taxes. Was it...

Select one answer only.

1. $\$ 35,000$ to $\$ 39,999$

2. $\$ 40,000$ to $\$ 49,999$

3. $\$ 50,000$ to $\$ 59,999$

4. $\$ 60,000$ to $\$ 74,999$

5. $\$ 75,000$ to $\$ 84,999$

6. $\$ 85,000$ to $\$ 99,999$

7. $\$ 100,000$ to $\$ 124,999$ 
8. $\$ 125,000$ to $\$ 149,999$

9. $\$ 150,000$ to $\$ 174,999$

10. $\$ 175,000$ or more

D. YOUR HOUSING AND UTILITIES

\section{Base: All Qualified respondents}

Q44 [S]

How much is your monthly rent or mortgage loan payment?

1. I do not pay rent or have a mortgage loan payment. SKIP TO Q58

2. Less than $\$ 500$

3. $\$ 501$ to $\$ 1000$

4. $\$ 1001$ to $\$ 1500$

5. $\$ 1501$ to $\$ 2000$

6. More than $\$ 2000$

Base: IF $Q 44=2-6$ or $44=$ missing

Q45 [S]

Was there any time in the past 12 months when you did not pay the full amount of the rent or mortgage?

1. Yes

2. No

\section{Base: All Qualified respondents}

\section{Q46 [S]}

Was there any time in the past 12 months when you did not pay the full amount of the gas, oil, electricity, or water bills?

1. Yes

2. No

Base: $\mathrm{Q} 46=1$ or $\mathrm{Q} 46=$ missing

Q47 [S]

In the past 12 months, did the gas or electric company turn off service, the oil company not deliver oil, or the city turn off your water??

1. Yes

2. No

\section{Base: All Qualified respondents}

\section{Q48 [S]}

In the past 12 months, did your telephone company disconnect service because payments were not made? 
1. Yes

2. No

\section{F. YOUR JOB}

\section{Base: All Qualified respondents}

Q49 [M]

Now some questions about what you do. Are you...?

1. Working now ask $50,51,52$

2. Only temporarily laid off, or on sick or maternity leave skip to 68 unless also report working now

3. Looking for work, unemployed skip to 68 unless also report working now

4. Retired skip to 68 unless also report working now

5. Permanently or temporarily disabled skip to 68 unless also report working now

6. Keeping house skip to 68 unless also report working now

7. A student skip to 68 unless also report working now

8. Other (please specify) skip to 68 unless also report working now

Base: $Q 64=1$ or $Q 64=$ missing

\section{Q50 [S]}

How did you usually get to work last week? If you usually used more than one method of transportation during the trip, select the option used for most of the distance.

1. Worked at home SKIP TO 68

2. Walk

3. Bike

4. Your own personal vehicle (e.g., car, truck, SUV)

5. The personal vehicle of a friend, family member, or neighbor

6. Taxi service or rideshare (e.g., Uber, Lyft)

7. Rental car or car sharing service (e.g., zipcar, Car2go)

8. Bus

9. Train or subway

10. Paratransit

11. Other (please specify) [TEXTBOX]

Base: $(Q 64=1$ or $Q 64=$ missing $)$ and $Q 66$ ne 1

\section{Q51 [NUMBOX, 0-999]}

How many minutes did it usually take you to get from home to work last week? minutes

\section{G. YOUR SOCIAL SUPPORT/SERVICES}




\section{Base: All Qualified respondents}

\section{Q51 [Grid, SP across]}

Sometimes people are not able to do the things they want to do. In the past 12 months, which of the following were you not able to do when you wanted to?

Statements in row:

1. I did not go see a doctor or medical professional when I wanted to.

2. I did not go to religious services when I wanted to.

3. I did not go to a court appointment when I wanted to.

4. I did not go to get help with food, clothing, or shelter when I wanted to.

5. I did not go to a community meeting when I wanted to.

6. I did not go to the grocery store when I wanted to.

7. I did not look for a new place to live when I wanted to.

8. I did not look for work when I wanted to.

9. I did not pay a bill when I wanted to.

10.I did not vote when I wanted to.

Statements in column:

1. Yes

2. No

\section{SCRIPTER: Insert KP closing question.}

If you have additional comments about how you get from place to place or any problems you have with transportation, please provide them below.

\section{END OF QUESTIONNAIRE}




\section{REFERENCES}

Arcury, T., J. Preisser, W. Gesler, and J. Powers. 2005. "Access to Transportation and Health Care Utilization in a Rural Region.” The Journal of Rural Health 21 (1): 31-38.

Blumenberg, E., and A.W. Agrawal. 2014. "Getting around When You're Just Getting by: Transportation Survival Strategies of the Poor." Journal of Poverty 18 (4): 355-78.

Callegaro, M., and C. DiSogra. 2009. "Computing Response Metrics for Online Panels.” Public Opinion Quarterly 72 (1): 1008-32.

Campbell, C. 1991. "Food Insecurity: A Nutritional Outcome or a Predictor Variable?" The Journal of Nutrition 121 (3): 408-15.

Carlson, S., Andrews M., and G. Bickel. 1999. "Measuring Food Insecurity and Hunger in the United States: Development of a National Benchmark Measure and Prevalence Estimates.” The Journal of Nutrition 129(2): 510S-516S.

Coleman-Jensen, A., M. Rabbitt, C. Gregory, and A. Singh. 2017. "Household Food Security in the United States in 2016." ERR-237, U.S. Department of Agriculture, Economic Research Service.

DeVellis, R.F. 2017. Scale Development: Theory and Applications. Los Angeles: SAGE Publications.

DiSogra, C., Callegaro M., and E. Hendarwan. 2009. "Recruiting Probability-Based Web Panel Members Using an Address-Based Sample Frame: Results from a Pilot Study Conducted by Knowledge Networks.” In 2009 Joint Statistical Meeting. Washington D.C.

Fitzpatrick, K., and M.Ver Ploeg. 2010. "On the Road to Food Security? Vehicle Ownership and Access to Food." In The Panel Study of Income Dynamics's Conference on SES and Health Across Generations and Over the Life Course. Ann Arbor, MI. http://sites.nationalacademies.org/cs/ groups/dbassesite/documents/webpage/dbasse_084304.pdf.

Frongillo, E. 1999. "Validation of Measures of Food Insecurity and Hunger." The Journal of Nutrition 129 (2): 506S-509S.

Frongillo, E., B. Rauschenbach, C. Olson, A. Kendall, and A. Colmenares. 1997. "QuestionnaireBased Measures Are Valid for the Identification of Rural Households with Hunger and Food Insecurity." The Journal of Nutrition 127 (5): 699-705.

Goswami, N., M. Schmitz, T. Sanchez, S. Dasgupta, P. Sullivan, H. Cooper, D. Rane, J. Kelly, C. Rio, and L. Waller. 2016. "Understanding Local Spatial Variation along the Care Continuum: The Potential Impact of Transportation Vulnerability on HIV Linkage to Care and Viral Suppression in High-Poverty Areas, Atlanta, Georgia." Journal of Acquired Immune Deficiency Syndromes 72 (1): $65-72$.

Gould-Werth, A. 2015. "Public Benefits and Private Safety Nets: Demographic Disparities in Resources Following Job Loss.” Doctoral dissertation., Ann Arbor: University of Michigan.

Grengs, J. 2012. "Equity and the Social Distribution of Job Accessibility in Detroit." Environment and Planning B: Planning and Design 39 (5): 785-800.

Muthén, L.K., and B.O. Muthén. 1998. Mplus User's Guide. 7th ed. Los Angeles, CA: Muthén \& Muthén.

National Research Council. 2006. Food Insecurity and Hunger in the United States: An Assessment of the Measure. Washington, D.C: The National Academies Press. 
Nord, M., and M. Prell. 2007. "Struggling to Feed the Family: What Does It Mean to Be Food Insecure?" Amber Waves 5: 23-29.

Nunnally, J.C. 1978. Psychometric Theory. 2nd ed. New York: McGraw-Hill.

Pendall, R., C. Hayes, A. George, Z. McDade, C. Casey Dawkins, J.S. Jeon, E. Knaap, E.

Blumenberg, G. Pierce, and M. Smart. 2014. Driving to Opportunity: Understanding the Links among Transportation Access, Residential Outcomes, and Economic Opportunity for Housing Voucher Recipients. Washington D.C: The Urban Institute.

Radimer, K., C. Olson, and C. Campbell. 1990. "Development of Indicators to Assess Hunger." The Journal of Nutrition 120 (11S): 1544-48.

Sagrestano, L., J. Clay, R. Finerman, J. Gooch, and M. Rapino. 2014. "Transportation Vulnerability as a Barrier to Service Utilization for HIV-Positive Individuals." AIDS Care 26 (3): 314-19.

Smart, M., and N. Klein. 2015. "A Longitudinal Analysis of Cars, Transit, and Employment Outcomes.” San Jose, CA: Mineta Transportation Institute Publications.

Syed, S., B. Gerber, and L. Sharp. 2013. "Traveling towards Disease: Transportation Barriers to Health Care Access.” Journal of Community Health 38 (5): 976-93.

Yeager, D.S., J.A. Krosnick, L. Chang, H.S. Javitz, M.S. Levendusky, A. Simpser, and R. Wang. 2011. "Comparing the Accuracy of RDD Telephone Surveys and Internet Surveys Conducted with Probability and Non-Probability Samples.” Public Opinion Quarterly 75 (4): 709 -gfk747. 